Rhode Island College

Digital Commons @ RIC

Master's Theses, Dissertations, Graduate

Master's Theses, Dissertations, Graduate Research and Major Papers Overview

Research and Major Papers

$5-1-2013$

\title{
Contributing Factors to Hospital Readmissions
}

Susan M. Amalfitano

Rhode Island College

Follow this and additional works at: https://digitalcommons.ric.edu/etd

Part of the Nursing Commons

\section{Recommended Citation}

Amalfitano, Susan M., "Contributing Factors to Hospital Readmissions" (2013). Master's Theses, Dissertations, Graduate Research and Major Papers Overview. 215.

https://digitalcommons.ric.edu/etd/215

This Major Paper is brought to you for free and open access by the Master's Theses, Dissertations, Graduate Research and Major Papers at Digital Commons @ RIC. It has been accepted for inclusion in Master's Theses, Dissertations, Graduate Research and Major Papers Overview by an authorized administrator of Digital Commons @ RIC. For more information, please contact digitalcommons@ric.edu. 
CONTRIBUTING FACTORS TO HOSPITAL READMISSIONS

\author{
by \\ Susan M. Amalfitano \\ A Major Paper Submitted in Partial Fulfillment \\ Of the Requirements for the Degree of \\ Master of Science in Nursing \\ in \\ The School of Nursing \\ Rhode Island College
}

2013 


\begin{abstract}
Aims and objectives. To investigate the elderly patient's perspective about the reasons for discharge to home being unsuccessful, resulting in rehospitalization.

Background. Elderly patients have a high rate of readmission to the hospital within 30 days of discharge. Starting in October of 2013, hospitals having a high rate of readmission of patients with heart failure (HF), myocardial infarction (MI), and pneumonia (PNA) will face financial penalties. Evidence indicated that by utilizing risk prediction tools and incorporating transition interventions the risk of a hospital readmission may be reduced.
\end{abstract}

Design. A qualitative, descriptive design was used.

Methods. In 2013, a student investigator interviewed elderly patients over the age of 65 who were readmitted to the hospital with the diagnosis of HF, MI, PNA or chronic obstructive pulmonary disease (COPD) within 30 days of discharge. A total of six $(\mathrm{N}=6)$ patients and/or surrogates participated in the interviews. Data were collected using semistructured interviews and subjected to thematic content analysis.

Results. Three major themes emerged: discharge readiness, communication, and education.

Implications for the advanced practice registered nurse (APRN). Practicing in an APRN role provides the opportunity for the nurse to facilitate the appropriate transitional care of elderly patients placing them at less risk for hospital readmission within 30 days. 


\section{Table of Contents}

Table of Contents..............................................

Statement of Problem...................................................

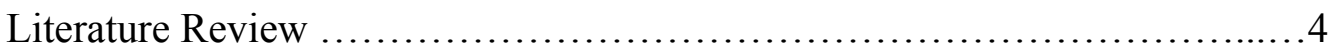

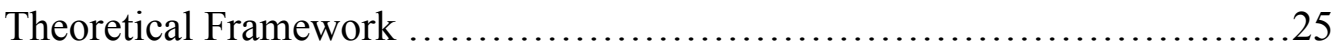

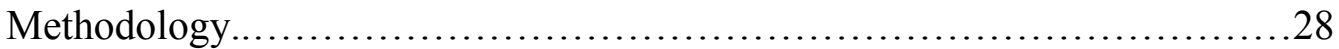

Results.......................................................... 36

Summary and Conclusions...........................................42

Implications for Advanced Nursing Practice...........................45

References........................................................49

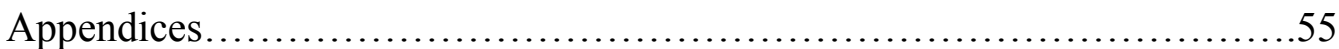




\section{Background/Statement of Problem}

Elderly patients who are discharged to home following an acute care hospitalization have a high probability of being readmitted to the hospital within thirty days of discharge. These vulnerable patients are at risk for potential breaches in their health care continuum and are in jeopardy of adverse health outcomes (Forster, Clark, Menard, Dupuis, Chernish, Chandok, Khan \& van Walraven, 2004). Hospitalization can result in physical and emotional trauma for the elderly patient, such as increased risk of hospital-acquired infections, trauma due to falls, decrease mobility, depression, anxiety and delirium. Various causes of hospital readmissions have been identified, including the patient's misunderstanding of the discharge instructions, medication omissions or duplications, lack of communication between the hospital and primary care physician, and lack of continued home care and support services (Jenq \& Tinetti, 2012). Older adults may suffer from "post-hospital syndrome." Not only is the patient recuperating from an acute illness, but during their hospitalization, they may have been sleep deprived, have had an alteration in their nutrition and hydration status, are still experiencing pain or discomfort, have received medications that altered their mental status, and/or have become deconditioned from inactivity (Krumholz, 2013).

The case management staff at The Miriam Hospital in Providence, RI, was surveyed about their perceived reasons for the frequent readmissions to the hospital of the elderly patient population. Their perceptions included: the patient being discharged from the hospital before being medically stable, a lack of understanding of the patient's discharge instructions by patient and family, failure to follow through with their licensed- 
care provider appointments, and non-compliance with the directives regarding medication, whether it be a cost factor or misunderstanding of the medication regime (The Miriam Hospital, Case Management staff, September, 2012).

In the United States (U.S.), 19.6\% of Medicare fee-for-service beneficiaries are readmitted to the hospital within 30 days. Hospital readmission rates vary by demographic locations, with Rhode Island at 19.8\% (Jencks, Williams \& Coleman, 2009). Health care cost in the US continues to escalate, with hospital care being a major contributor. Many stakeholders are interested in reducing the number of hospital readmissions in an effort to both to reduce cost and improve outcomes (Ahmed and Rak, 2010). The Medicare Payment Advisory Council (MedPAC), an independent Congressional agency, estimated that preventable rehospitalizations may cost as much as \$12 billion per year (Hackbarth, 2009).

In the U.S., hospital readmissions and health care outcomes have been receiving amplified attention. The Centers for Medicare and Medicaid Services (CMS) define a readmission as "an admission to a subsection hospital within 30 days of a discharge from the same or another subsection hospital" (Centers for Medicare and Medicaid Services, 2012). Given the severity of this problem and the financial implications, hospital-based health care providers have a responsibility to investigate innovative ways to ensure each patient's discharge needs are addressed with a feasibility plan for implementation prior, appropriate post-hospital services are in place, discharge instructions are understood and there is a feasible plan for implementation, and follow-up appointments are arranged that 
suit the abilities of the patient (Berry, Costanzo, Elliot, Miller, Miller, Quackenbush \& $\mathrm{Su}, 2011)$.

Beginning January 1, 2013, new Medicare codes regarding the roles of nursing and care coordination went into effect. Medicare recognizes that activities performed by Registered Nurses (RNs) can improve patient outcomes and reduce hospital readmissions, thereby saving money. This recognition has the potential of to create $\mathrm{RN}$ positions that fulfill the identified need of transitional care coordinators. Registered nurse practitioners, clinical nurse specialists, certified nurse midwives and other primary care professionals will be awarded new payments for "transitional care management" services that are provided within 30 days of hospital discharge (American Nurses Association, 2012).

The purpose of this project was to investigate the patient's perspective about the reasons for discharge to home being unsuccessful, resulting in rehospitalization within 30 days. 


\section{Review of Literature}

\section{Databases}

A literature search of the following databases was conducted: CINAHL, Medline, Cochrane Collaborative, OVID HealthStar, OVID Nursing and PsychInfo. Dates include 2000-2013 and key words searched were: hospital readmissions, case management, hospital, elderly, aged, discharge planning, family caregivers, and geriatric nursing. A total of 349 entries were identified.

\section{Medicare and Hospital Readmissions}

Historically, Medicare has paid for all hospital readmissions except those in which a patient was readmitted with the same diagnosis as their initial hospitalization less than 24 hours after discharge. Given the high cost of hospital readmission, Medicare has proposed to reduce the rate of payments to hospitals. The Medicare Payment Advisory Commission (MedPAC) recommended that hospitals with high risk-adjusted rates of rehospitalization receive lower average per case payments (Harkbarth, 2009).

Patients are readmitted to the hospital after both medical and surgical interventions. A fifteen month study, by Jencks, Williams and Coleman (2009), reviewed records of patients enrolled in the Medicare fee-for-service program. The researchers reviewed rehospitalization rates among 13,062,937 potential patients from 4,926 acute care settings. Not including the population that either died or were transferred to another acute care setting, there were $11,855,702$ patients who were at risk for rehospitalization. Thirty four percent were readmitted within 90 days and $56.1 \%$ were readmitted within 365 days. The researchers also looked at the reason for rehospitalization for these 
patients. $84.4 \%$ were readmitted for medical conditions and $72.6 \%$ were readmitted after discharge following surgical interventions. The most common reasons for medical readmissions were heart failure and pneumonia. Other diagnoses included chronic obstructive pulmonary disease (COPD), psychoses and gastrointestinal problems. Patients who were readmitted after surgical procedures also had heart disease and pneumonia as the most frequent reason for rehospitalization. Other reasons accounted for post-operative readmissions related to procedures, for example, cardiac stents, major hip or knee surgery, vascular or bowel surgery.

The same study identified geographic patterns of the fifty U.S. states and two territories, finding that the readmission rate within 30 days was $45 \%$ higher in the five states with the highest rates than in the five states with the lowest rates (See Appendix I) (Jencks et al, 2009).

Elderly patients who were readmitted to the hospital with the diagnoses of heart failure, acute myocardial infarction and pneumonia had a higher probability of being readmitted within the first 15 days of discharge from the initial hospitalization (Dharmarajan et. al, 2013). Investigators evaluated data from 2007-2009 on Medicare fee-for-service claims data. They analyzed timing of hospitalization and demographic characteristics. Of 1,330,157 patients that were hospitalized for heart failure, 329,308 patients (24.8\%) were readmitted within 30 days. They identified 108,992 out of 548,834 (19.9\%) of patients who were readmitted within 30 days with acute myocardial infarction. The number of patients who were readmitted within 30 days with pneumonia was 214,239 out of $1,168,624(18.3 \%)$. Of all of the 30 -day readmissions, they found 
that $61 \%$ of the heart failure patients, $67.6 \%$ of the acute myocardial infarction patients and $62.6 \%$ of the pneumonia patients were readmitted during the fifteen days following discharge. The researchers collected demographic data along with timing between discharge and readmission and diagnosis, including age categories $(65-74,75-85$, and over age 85), gender and race. They concluded that the readmission diagnoses were similar regardless of age, gender, race or time after discharge (Dharmarajan, et al, 2013).

Because of the significance between timing of hospital discharge and readmission in both studies, this research project focused on the instances of 30-day hospital readmission for patients readmitted with heart failure, pneumonia, and myocardial infarction.

\section{Predicting the Risk of Hospital Readmission}

The Miriam Hospital, a 247-bed facility located in Providence, RI, implemented a "Transitions" team to prevent the avoidable rehospitalization of patients with heart failure. The team identified before discharge patients who were at high risk for readmission by utilizing a Risk Stratification Tool for this population of patients. Patients were monitored for cognitive impairment and heart failure. Teaching was done through a "teach back" method. Patients were also called after discharge, to answer any questions and assure they were able to follow their medication regime and dietary restrictions. High risk patients were referred to appropriate home health agencies that utilized tele-health, as appropriate. Heart failure patients had their follow-up physical appointments booked prior to discharge from the hospital, after ensuring the day and time of the appointment was feasible for the patient. The team worked with area skilled 
nursing facilities to form a transitions partnership with their medical directors, who were an integral part of the team. They also introduced and incorporated palliative care when appropriate (Karen Joost, RN, Director of Inpatient Services, October 11, 2012).

A patient's comorbidities increase the risk factors for hospital readmissions. A study by Lagoe, Noetscher, and Murphy (2001) identified such risk factors. The study included hospitalized inpatients in four acute care facilities. This retrospective quantitative study examined two 12-month periods in 1998 and 1999. A readmission was defined as a patient who returned for an inpatient stay for at least one day and readmission occurred within thirty days of the initial admission discharge. Patients who had an elective or planned readmission were excluded. The researchers identified readmissions that occurred for a diagnosis-related group (DRG) within the same major diagnostic category as the initial admission. The readmission statistics for the study population were identified by the number of inpatient admissions and were calculated for major variables such as secondary diagnoses, severity of illness, length of stay, discharge status (self-care, home care, nursing home, other), age, gender, ethnicity and residence. Initially, the analysis focused on the incidence of risk of readmission for patients with congestive heart failure. The highest number of readmissions was among patients with heart failure and one or more of the following co-morbidities: diabetes, renal failure and cardiomyopathy. Notably it was found that patients in the age groups 60 to 69 years and 70 to 79 years had readmission rates 35.4 percent higher than those of the total study population (Lagoe, Noetscher \& Murphy, 2001). 
External factors have also been studied as predictors for hospital readmission (Dobrzanska and Newell, 2006). Contributing factors were explored for patients, ages 77 years and older, who were emergently readmitted to the hospital within 28 days of discharge. The goal was to identify variables and correlations using a descriptive design. A pilot study and main study were completed at two National Health Service (NHS) hospitals in the United Kingdom. Using a structured data collection tool, researchers gathered information from patient records. Variables examined included: length of stay on the index admission, length of stay on readmission, source of readmission, destination following discharge, reasons for readmission, diagnosis, and hour, day month and mode of readmission. The readmission rate was high at $13.4 \%$ for the three month pilot study, prompting a year-long study. In the main study, 109 out of 1235 patients who were admitted to the hospitals were readmissions $(8.82 \%)$. The average age of the readmitted patient was 83.61 years. In both the pilot and the main studies, females were more likely to be readmitted ( $62 \%$ female, $38 \%$ male). The researchers developed a framework of patient and external factors that were found to increase the likelihood of hospital readmissions. The external factors that increased the likelihood of readmission were if a patient was discharged on a weekend or a bank holiday after an initial admission of less than 72 hours in length. Patient factors that increased the likelihood of readmission were: diagnosis of respiratory or cardiac disease, living alone, no social service input and living in a care setting. The authors concluded that when an older person is admitted to the hospital and the above risk factors are identified, post-discharge care interventions should be instituted to help decrease hospital readmissions (Dobrzanska and Newell, 2006). 
Hospitals can reduce readmissions by examining each patient's risk factors for hospital readmission utilizing a risk prediction tool, combined with exploring external factors specific to the culture, as listed in the above study.

\section{PPACA and Hospital Readmissions}

Congress deliberated on methods to contain Medicare spending while improving the quality of care delivered. Estimates of future spending on hospital services indicated steady growth; so the House and Senate targeted Medicare spending on hospitalizations as an appropriate approach to reducing Medicare spending. The Patient Protection and Affordable Care Act (PPACA) was signed into law by President Barack Obama in March of 2010. The health care reform bill addressed many aspects of health care payment and health prevention strategies, including containment of the cost of hospital readmissions by Medicare recipients (Stone \& Hoffman, 2010).

The Hospital Readmission Reductions Program, a component of a cost containment measure of PPACA was designed to reduce CMS payments to hospitals that had excessive readmissions. The program was initiated for patients who were discharged on or after October 1, 2012 (CMS, 2012). Hospitals that had comparatively high readmission rates for patients with pneumonia, myocardial infarction and heart failure will have financial penalties levied against them with CMS estimating to recover $\$ 280$ million from those hospitals (Rau, 2012).

The hospitals with a high rate of readmission will face a financial burden. As a result hospitals are striving to implement and evaluate measures to prevent readmissions, but some causes for readmission may be beyond the control of the hospitals. If the rates 
of readmission reflect poor quality care, then standards can be implemented to improve patient care. However, other important drivers of hospital readmissions include mental illness, poor social support system and poverty (Joynt \& Jha, 2012). Hospital readmissions caused by one or more of these factors are situations that the hospital cannot alter.

Since the passage of PPACA, there has been an increase in interest in Accountable Care Organization models (ACOs). Accountable Care Organizations are partnerships, comprised of health care providers that contract through CMS. ACOs assist with coordination of care, track the health status of patients, remind patients of follow-up appointments and generate analytical reports regarding diagnoses and demographic data of patients. To be eligible for Medicare bonuses, ACOs must also submit data on 33 quality measures (Terry, 2012). A valuable tool that is used by the ACO model is predictive modeling $(\mathrm{PM})$. Predictive modeling is "a tool that can be used to determine which patients might be at high risk for coming back through that revolving admissions door" (Meek, 2012). The aim is to recognize individuals who are at-risk for adverse outcomes that then result in hospital readmission. As Meek reports, there has not been a financial motive for preventing readmissions prior to PPACA. The challenge of PM confronts not only doctors, but staff nurses and hospital case managers as well. For PM to be successful, a care collaboration team must assess a patient's/family's ability to provide post-hospital care, noting their perceptions of illness and disease management. Meek suggests developing a PM tool using the following techniques:

- Review literature about readmission factors for specific disease conditions

- Develop a readmission screening tool for testing purposes 
- Gather the predischarge test survey on a sufficiently large population

- Gather readmission data on the same group of patients

- Develop and verify the PMs using regression techniques

- Streamline the readmission test

A readmission screening survey may serve as a guideline for making discharge decisions. The PM tool may be an essential component in preventing avoidable rehospitalizations. If a patient is identified as being at-risk for readmission, a decision may be made to keep the patient in the hospital for a longer period of time or a discharge disposition may need to be revised, for example, a patient may require a short-term stay in a skilled nursing facility before going home (Meek, 2012).

Hospitals and acute care settings utilize different models and tools to calculate and report risk prediction for readmission. A systematic review by Kansangara, Englander, Salanitro, Kagen, Theobald, Freeman \& Kripalani (2011) was executed to describe the performance and clinical and administrative suitability of these risk prediction models. The researchers selected 286 articles for review; most were based on U.S. health care data, but there were also studies included from England, Australia, Ireland, Switzerland and Canada. The factor most often reported among the studies was the 30-day readmission rate. Sample sizes in these studies ranged from 173 patients to over 2.7 million patients. The systematic review found 26 different readmission rate risk prediction models being used in different settings and with different populations. Only one model attempted to identify potentially preventable readmissions. Half of the prediction models were designed for hospital comparison purposes. The other half was designed to identify high-risk patients who may benefit from a transitional care 
intervention. The researchers reported that both types of models had a poor predictive ability (Kansangara et al., 2011).

As seen in the literature, hospital readmissions have proven both costly to Medicare and insurance companies. Risk prediction modeling has emerged as a strategy to attempt to reduce readmission rates, but this appears to have had limited success. The following literature will review different type of "transitions" programs implemented to reduce the number of hospital readmissions.

\section{Transitional Care Interventions}

Transitional care interventions that will be reviewed are patient education, a Hospital-to-Home Program, a Re-engineered Discharge (RED) Program, Telemedicine and ehealth, case management, patient and caregiver support, and nursing/patient staffing levels and the percentage of nursing staff with an earned Bachelor of Science (BS) in nursing.

\section{Education.}

Enhanced discharge education by nurses of patients with chronic heart failure (HF) significantly reduces the readmission rate of these patients (Koeling, Johnson, Cody \&Aaronson, 2005). The study was conducted to determine if a discharge patient education program would improve clinical outcomes in chronic heart failure (HF) patients. In the study, 223 participants were randomly assigned to receive standard discharge information (control, $n=116)$ or standard discharge information plus an 
enhanced educational intervention (education, $n=107)$. The participants in the control group received the standard written discharge information from their nurses. The contents of the standard packet included information about the patient's medications and dosages, drug/food interactions and potential side effects. It also included dietary and weight monitoring instructions and a booklet explaining heart failure. Participants receiving the intervention were visited by a nurse educator for a 60 minute period before discharge. The nurse educator discussed the educational materials that explained the causes of heart failure, the rationale for the medication regime,-the importance of preventing fluid overload, and the relationship to the adherence to a sodium-restricted diet. Patient education also included self-care behavior such as daily weight monitoring, smoking cessation and avoidance of heavy alcohol intake. Participants were given heart failure guidelines, written in layman's terms. During the enrollment session, participants were contacted by telephone at 30,90 and 180 days after discharge, and administered questionnaires regarding hospital readmissions, medications, heart failure-related quality of life and self-care knowledge. The patients who received the enhanced educational sessions had end point results of rehospitalization or death reduced by $35 \%$, as compared with the patients who received the standard heart failure discharge education (Koeling, Johnson, Cody \&Aaronson, 2005).

The number of hospital readmissions for patients with heart failure has also been found to be reduced when patients are given the comprehensive discharge instructions, as required by The Joint Commission (TJC) (Van Such, Naessens, Stroebel, Huddleston \& Williams, 2006). Researchers studied whether patients who received discharge 
instructions that had been developed with the intention of reducing readmissions actually had effect on readmission status. Of 1,121 patients who were discharged with a primary diagnosis of heart failure, 782 patients met TJC's criteria for receiving discharge instructions. Documentation was found of the following types of instructions: medication, weight monitoring, worsening symptoms, activity, follow-up appointment, and diet. Sixty-eight percent of patients were documented as receiving all six types of instructions. Six percent did not have documentation of receiving any type of discharge instructions. Within 30 days, $16 \%$ of the 782 patients were readmitted for heart failure. The authors concluded that patients who received all instructions (68\%) were significantly less likely to be readmitted for any cause including heart failure than those who missed at least one type of instruction (Van Such, Naessens, Stroebel, Huddleston \& Williams, 2006).

The implications of these two studies show the importance of patient education and comprehension of their discharge instructions in preventing hospital readmissions.

\section{Hospital-to-Home Program.}

The Hospital-to Home Program provided frail elderly (age 65 and older) with an in-home visit from a social-worker-navigator within 72 hours after discharge from the hospital. This visit determined that the patient/family understood the discharge instructions and were able to implement them with the support of home care services. The patient/family were also provided the opportunity to explore other ways that a successful transition could occur. Post discharge the patients were followed from 30 days 
up to four months. This sample experienced a $61 \%$ reduction in hospital readmission rate, at a cost savings of $\$ 682,202$ per year (Watkins, Hall \& Kring 2012).

\section{RED Program.}

Patients who received enriched in-patient education, a written care plan that, included discharge and medication instructions, and contact information to reach their health care team, as well as post-discharge follow-up showed significantly fewer emergency department (ED) visits and a lower number of hospital readmissions (Jack, et al., 2009). At Boston Medical Center in Boston, Massachusetts, researchers evaluated the effects of the Reengineered Discharge (RED) program. While the study's participants were ages 18 years and older, the results paralleled that of the studies of older adults. For the study, patients were randomly assigned to one of two groups: the intervention group and the usual care group. Nurse discharge advocates (DAs) were hired to coordinate discharge planning with the hospital team and to educate and prepare patients for discharge. The in-hospital interventions of the RED program included disease education throughout the hospital stay, scheduling and coordinating follow-up appointments, stressing the importance of keeping the appointments, discussing laboratory results and diagnostic testing, organizing post-discharge services, confirming medication regime and discharge plan, communicating discharge summaries and important findings to the appropriate services, and assessing the degree of the patient's comprehension. The participants who to completed the RED program had a $30 \%$ lower 
rate of ED visits and hospital readmissions within 30 days of discharge than those receiving the usual care. The estimated cost savings for the actual hospital cost and estimated outpatient cost was 33.9\% for the intervention group (Jack et al., 2009).

\section{Telemedicine and eHealth.}

When a clinician and a patient are not in the same location, telemedicine can be implemented. Telemedicine, synonymous with ehealth, is the use of electronic communications and information technologies to improve health outcomes. Types of remote health delivery systems can be used for specialist referral services, direct patient care, remote patient monitoring, medical education and mentoring, and providing consumers with medical health information (American Technology Association, 2006).

An interactive voice response (IVR) system, when used in addition to the usual case management services received by patients after discharge, assisted in the reduction of 30-day hospital readmission rates. In a study at the Geisinger Health System (GHS) in northeastern Pennsylvania, the Geisinger Monitoring Program (GMP) was used, this is an interactive voice response system (IVR). The case manager contacted eligible patients and inquired about medication compliance, falls, fever, gastrointestinal symptoms, shortness of breath, edema, neurological symptoms, psychosocial support, and incision site complications (if applicable). If it was determined that a patient was a high readmission risk, they were enrolled in the program. Patients were excluded from the program if they were cognitively impaired, had severe hearing impairment, or were not able to receive planned telephone calls. Patients then received an IVR call once weekly for 30 days for a total of four calls. A total of 875 Medicare patients were enrolled in the 
GMP program, in addition to being enrolled in the case management program. These patients were compared with 2420 matched control patients who received only case management services. The researchers reported that the patients who used the GMP with case management had a $44 \%$ reduction in 30 -day readmission rates and concluded that investing in automated monitoring systems may reduce hospital readmissions (Graham, Tomcavage, Salek, Sciandra, Davis \& Stewart, 2012).

Reduced hospital readmissions were also seen in participants of a telephonic Transitional Case Management (TCM) program that helped identify gaps in patient care. Case managers from a large national health care organization telephoned patients within three business days of discharge and followed study protocol for these follow-up phone calls. If a patient agreed to participate in the study, a case manager used specific tools to identify and remedy gaps in care. Readmission rates were calculated and compared for those participating in the TCM program during the same time periods. The two groups were similar to each other in regard to age, sex and cause of initial admission. The researchers found reduced readmission rates within 30 days of the patients who received the TCM program $12.66 \%$, as compared to $35.85 \%$ for the group that received no intervention (Ahmed \&Rak, 2010).

\section{Case Management.}

Most members of hospital health care teams are aware of the case managers in the hospital and their role in discharge planning. Case managers frequently become familiar with patients who are regularly admitted to the hospital and often listen to the patient/family feedback to learn the reasons for readmission. Experienced case managers 
are aware of post-hospitalization services available to patient/families and may suggest appropriate skilled, non-skilled, acute or sub-acute aftercare ("Take steps now to reduce hospital readmissions," 2009). Some factors that affect hospital readmission rates include sociodemographic factors, such as age, living environment or educational level, patient adherence factors, severity of illness and condition-specific factors (AskrenGonzalez \& Frater, 2012).

Discharge management by trained social workers or nurses may result in fewer elderly patients being institutionalized in a nursing home in the first days after hospital discharge (Steeman, Moons, Milisen, de Bal, de Geest, de Froidmont, Tellier, Gossett \& Abraham, 2006). A quasi-experimental study was done to evaluate whether the application of "discharge management" reduced hospital readmissions and institutionalization of geriatric patients. A total of 824 patients were assigned to a control or an experimental group. Patients were screened for risk by an assessment tool that was developed for the study. Participants were excluded if they resided in a nursing home. The experimental group $(n=355)$ received comprehensive in-hospital discharge planning, according to case management protocol. The control group $(n=469)$ received "usual care." Results demonstrated that individuals in the experimental group had considerably more discharges to their own home as opposed to a nursing facility when compared to the usual care group. Only $14.9 \%$ of patients were institutionalized in the discharge management group, as compared to $23.7 \%$ in the usual care group.

The researchers reported that the patients assigned to the usual care group had nearly double the readmission rate by 15 days post-discharge, but the number of 
readmissions between 15 and 90 days was not significantly different among the groups (Steeman et al., 2006).

A study by Schmeida \& Savrin (2012) explored readmission data for patients who had a 30-day rehospitalization with a diagnosis of pneumonia. The researchers explored acute care hospitals in states having a pneumonia readmission rate that were higher than the US national rate. They found that two key variables: (1) correct prescription of initial antibiotic(s) and (2) correct discharge information being given to the patient decreased the readmission rates in states ranking above the national average on pneumonia 30 -day readmissions. The authors suggest that case management needs to include programs aimed at preventing patient care disparities and should be monitored frequently to minimize disparities (Schmeida \& Savrin, 2012)

A follow-up study by Schmeida \& Savrin (2012) examined readmission data for patients who were rehospitalized with heart failure. The researchers explored acute care hospitals in states having heart failure readmission rates that were higher than the US national rate. They found that in the "worse" states patients had less access to prescription drug coverage. The authors suggested that case management interventions must be in place to secure post-discharge medications in order to avoid readmission for heart failure. Interestingly, they also found that states with a higher population of nonEnglish speaking patients had less occasion of being ranked "worse" on heart failure 30day readmission rates. Effective case management interventions targeting language health literacy may have been effective on reducing readmission. The researchers 
acknowledged that more research is required and that there needs to be improved access to services for persons with limited English proficiency (Schmeida \& Sarvin, 2012).

In the case management models reviewed, structured discharge planning that identifies at-risk patients may help reduce the incidence of avoidable hospital readmissions.

\section{Caregiver and Family Support.}

Frail elderly patients need caregiver support when they are discharged from the hospital. Coleman (2003) stated that patients with complex care needs and their caregivers must be aware of what to expect at the next care junction. Further, it is important to allow patients and caregivers to discuss their values and goals of care. Patients and caregivers need to be given educational tools that describe their medications, symptoms of disease progression and stress the importance of following-up with their health care provider (Coleman, 2003).

The inclusion of family members in discharge planning and education well before the date of hospital discharge has improved outcomes in frail elderly patients. Numerous internal and external factors can impact a patient's discharge plan. Researchers conducted a literature review to examine the best practices for hospital discharge for frail patients and their caregivers. Effective discharge planning involved careful patient assessment and care planning, patient and caregiver education, assessment and communication with both the patient and caregiver, inclusion of the family or caregiver in formulating a discharge plan, the discharge planning needs of the 
family, and family satisfaction with the discharge plan (Bauer, Fitzgerald, Haesler \& Manfrin, 2009).

A qualitative data analysis, similar to this project, was done in Australia to determine the factors contributing to emergency department (ED) readmissions from the perspective of patients who were over the age of 65 and who re-presented to the hospital ED within 28 days of discharge (Slayter, et al, 2013). The study was conducted in an acute medical unit (AMU) of 30 beds, where most of the patients were over the age of 65 . Purposeful sampling was used to recruit patients $(n=12)$, family caregivers $(n=15)$ and health professionals $(n=35)$. Participants were interviewed using a semi-structured format and audio-recorded, either in person or over the telephone, within three weeks of readmission. Data was collected from January, 2007 to September, 2007. Four themes emerged from the data: the health trajectory, communication challenges, discharge readiness, and the decision to return. The health trajectory, the most prominent theme, occurred in the context of the patient's symptoms, functional decline and significant caregiver involvement. Health care professionals described the patients as frail, with chronic acute conditions and comorbidities. The communication challenges described by patients and caregivers were the health professional remembering to give discharge instructions, as the content was vague. The health professionals described the AMU as being busy, and communication with the patients and caregivers was limited. The researchers reported diverse perceptions of discharge readiness. Most patients and caregivers tended to trust the health professionals to make discharge decisions. Most 
patients and caregivers reported that the decision to return to the hospital was a serious process, not to be taken lightly (Slayter, 2013).

The review of these studies highlights the importance of inclusion of family members or caregivers in the discharge process of the elderly patient.

\section{Nurse Staffing and Hospital Readmissions.}

There is a relationship between hospital nurse staffing levels, work environment and nurse education levels and the 30-day readmission rates among Medicare patients (McHugh \& Ma, 2013). The researchers studied patients between the ages of 65 and 89 who were readmitted with heart failure, myocardial infarction or pneumonia as their primary diagnosis. The results of the study revealed that $23.9 \%(n=39,954)$ of heart failure patients, $19.1 \%(n=12,131)$ of myocardial infarction patients and $17.8 \%$ $(n=25,169)$ of pneumonia patients were readmitted within 30 days. The higher the nurse patient-ratio, and the better the work environment, lowered the odds of a patient being readmitted. Nurses that provided direct care to patients gave the name of their employers, allowing the researchers to total responses by hospital. There were a total of 412 hospitals in the sample: California 210, Pennsylvania 134 and New Jersey 68. Participating nurses provided the number of patients and nurses on their last shift, allowing the researchers to calculate and average patient-to-nurse ratios. The nurses also gave their level of educational background. The researchers measured the nurse's work environment by utilizing Practice Environment Scale of the Revised Nursing Work Index. Hospitalization in a facility with a good versus poor work environment was associated with a 7\% lower readmission rate for heart failure patients, $6 \%$ lower for 
myocardial infarction patients and 10\% lower for pneumonia. The nurse's educational background was not significantly associated with readmissions among patients with heart failure or myocardial infarction. However, for patients with an admitting diagnosis of pneumonia, there was a 3\% lower risk of a 30-day readmission among hospitals for each 10\% increase of hospital nurses with a BSN-level education (McHugh \& Ma, 2013).

\section{Post-Discharge Program Model.}

A post-hospitalization discharge program that focuses on nurse-patient collaboration was proposed to reduce hospital readmissions. The program concentrates on communication and interpersonal relations between older adults with chronic disease and their nurses. The proponents of this model reported that older adults with chronic illness who experience stress, anxiety, or social isolation have a high risk of hospital readmissions. This model focuses on minimizing emotional distractions and increasing nurse-patient collaboration to improve lifestyle management. The emphasis is on four key elements of patient and nurse collaboration: construct, context, process and outcome. Construct includes creating a realistic patient-centered health promotion intervention to create or improve lifestyles, clarifying the components of the health program, and achieving and completing effective management in self-care and lifestyle. Context includes the nurses' expertise in management of chronic illness, experience as a facilitator, listening and empathetic understanding and the patients' own experiences. Process embraces minimizing the patients' major distractions including isolation, stress, conflict and depression. Outcome takes account of increasing knowledge to improve future patient care, continued nurses' support and reduced hospital readmissions. In this 
model, the program features a web of practice groups initially led by nurses that bring together former patients. Participants will be invited to share their stories about the challenges that they have encountered as adults with chronic diseases. The sessions will include education about improving diet, activity level, interpersonal communication and so that social isolation may be reduced, practicing relaxation techniques, and a process of motivational interviewing and goal-setting. Self-care and lifestyle stress assessments will be administered at a baseline and at 4-week intervals. The researchers project that throughout the sessions, nurses and patients would collaborate to recognize the value of health promotion activities and minimize to hospital readmissions (Glass, Moss \& Ogle, 2012). 


\section{Theoretical Framework}

The theoretical framework chosen to guide this study was Sister Callista Roy's Adaptation Model (Roy \& Andrews, 1999).

\section{Roy's Adaptation Model}

In Roy’s Adaptation Model (RAM), humans are regarded as biopsychosocial adaptive systems who cope with environmental change through the process of adaptation. The major assumptions, concepts and relationships of RAM are relevant to this research study, as it is based on the evolving patient's situation (Roy and Andrews, 1999).

In the model, the assumptions are classified as scientific or philosophical. Pertinent scientific assumptions in the study include:

- Awareness of self and environment is rooted in thinking and feeling

- System relationship includes acceptance, protections and fostering of interdependence

- Persons and environment transformation are created in human consciousness

- Integration of human and environment meanings results in adaptation

There are several defined concepts in the RAM. Concepts that are applicable to the study include the concept of environment. The physical surroundings of a patient affect the behavior of humans as adaptive systems. Health is an important concept and is defined as a state and process of being and becoming integrated and whole. The concept of person is defined as "a whole with parts that function as a unity for some purpose." 
Persons include groups, organization and society. Focal and contextual stimuli are outside forces in the environment which may affect a situation (Roy \& Andrews, 1999).

The RAM consists of four adaptive modes that serve as a framework for the model. They include the physiologic-physical mode, the self-concept group identity mode, the role function mode and the interdependence mode (diagram Appendix II).

The physiologic-physical mode concentrates on the physical changes achieved through adaptation to changes in needs. For example, an elderly patient may need an assistive device after hospitalization to achieve maneuverability in their environment. In this study, it would be important to recognize if the elderly patients are able to maneuver in their physical living environment without putting them at risk for falls or injury.

The self-concept-group identity mode focuses on psychological and spiritual integrity and a sense of purposefulness in the universe. An example may include a patient who has a new colostomy who is now unwilling to resume a previous group activity for fear of embarrassment. In this study, this mode may not have a significant effect on a patient's rehospitalization.

Role function mode fills the need for social integrity. That is knowing who one is, in relation to others. An elderly patient may feel useless in the family role if not able to perform previousfunctions or now needs assistance with tasks. If a patient is having feelings of depression, it may be difficult not to follow the prescribed discharge instructions or adhere to dietary restrictions, which may result in rehospitalization.

The interdependence mode reflects on the patient's close personal relationships and their adaptation to their relationships. For example, a personal relationship may 
evolve from being a daughter to becoming a caregiver to an aging parent. If the elderly parent is not able to adapt to a dependent role, they may not be willing to accept their child's role as a caregiver (Roy and Andrews, 1999).

In this study, the patient's response may involve the totality of the elderly patient's change(s) in physical, mental, emotional and spiritual health, as well as the physical environment the patient faces when he/she is discharged from the hospital to home. 


\section{Methodology}

\section{Purpose}

The purpose of the study was to explore factors that contribute to hospital readmission in older adults and to investigate the patient's perspective about the reasons his or her discharge to home was unsuccessful, as defined by rehospitalization within 30 days post-discharge.

\section{Design}

This study utilized an exploratory qualitative design. An interviewer administered a questionnaire verbally to patients and their surrogate, if present, in a oneto-one setting and the patients' verbal responses were recorded.

\section{Sample}

Eligible participants included patients: ages 65 and older, who were discharged to home and readmitted to the hospital within 30 days of discharge, and had a chronic disease diagnosis of HF, PNA, MI, and/or COPD. Exclusions included patients who were admitted to a critical care unit or discharged to another acute care setting, sub-acute setting, nursing home or assisted living facility. Also excluded were individuals with dementia or cognitive impairments. Patients who agreed to participate in the study were assessed for cognition by the student investigator using the Mini-Cog Assessment for Dementia (see Appendix III). The Mini-Cog is a reliable and valid measure used for dementia screening. It is appropriate to be used with older adults at various language, culture and literacy levels (Carolan Doerflinger, 2007). The possible score range is 0-3. 
A score of 3 is indicative of non-dementia. Patients were excluded from the study if their Mini-Cog score were positive for dementia or if they already had a dementia diagnosis.

A total of six patients met the criteria and were interviewed to explore the potential reasons for their hospital readmission.

\section{Site}

This study took place at The Miriam Hospital, a 247-bed teaching hospital in Providence, RI. Eligible patients were admitted to the medical/surgical units. The interviews took place in the patient's room or in a private conference room on the patient's unit.

\section{Procedures}

After obtaining permission for the study from the Rhode Island College and Lifespan Institutional Review Boards (IRBs), potential participants were identified using the Allscripts computer system. Allscripts provides a flag when a patient has been readmitted to the hospital within 30 days of discharge. Utilizing the electronic health record (EHR), the readmission diagnosis was examined to determine if it was related to the initial hospitalization diagnosis. The data collected before each initial interaction was the patient's age, gender, chronic disease diagnosis and length of time since the patient was discharged from the hospital. No identifying factors such as name date of birth, or social security number were collected.

The student investigator contacted the surrogate (family member, person holding the Durable Power Of Attorney for Health Care, or next of kin) for verbal consent to 
complete the Mini-Cog Assessment on the patient. The surrogate was contacted in person when visiting the patient in the hospital. The surrogate's identity was confirmed using the patient's demographic information sheet. Once verbal consent was obtained, the patient was approached by the student investigator and the study was explained. If the patient was in agreement, the Mini-Cog Assessment was administered by the student investigator.

If the patient did not score 3 out of 3 on the Mini-Cog Assessment, the patient was thanked and the encounter with the patient ended. If the patient scored a 0 to 2 , indicating a possible level of dementia, and if the surrogate was present, the surrogate was presented the Surrogate Informational Letter (Appendix IVa) and was asked to participate in the survey. If the surrogate was unwilling to participate, the patient and surrogate were thanked and the encounter ended.

If the patient scored 3 out of 3 on the Mini-Cog, the patient was presented the Informational Letter (Appendix IV). If the patient was willing to participate in the study, the interview commenced.

The patient was asked a series of questions (Appendix V). If the surrogate was present, it was explained that the patients' responses were key and the patient should be allowed to answer first, and the surrogate could comment later. The answers were recorded on paper during the interview, identifying key words that were amplified later. Tape recording of interviews was not considered as it may have been inhibiting to the patients. 
The Mini-Cog Assessment and interview required 30-60 minutes.

Since the student investigator is also a case manager at The Miriam Hospital, the interviews occurred after the student investigator's work hours or on her days off. With supervisory support, the student investigator did not case-manage the study participants during their hospitalization.

\section{Timeframe}

The proposal was presented to the Lifespan and Rhode Island College IRBs in September, 2012. Interviews began in February, 2013 and continued through the beginning of April, 2013.

\section{Organizational/Systems Factors: Enabling Factors and Barriers}

As a case manager, the student investigator had access and familiarity with Allscripts and the patient's electronic health record. Key stakeholders at The Miriam Hospital were notified of the study. A potential issue that was identified was that patient(s) who were case managed by the student investigator might feel uncomfortable participating in the study. To safeguard the potential study participant's autonomy and to avoid the appearance of a conflict, the Case Management Director made arrangements for alternate case management coverage for potential study participants.

A major barrier that was encountered during the study was the lengthy process of IRB approval from both Lifespan and RIC. The Lifespan IRB had concerns about obtaining consent from the elderly patient to administer the Mini-Cog without the surrogate's approval. It was deemed acceptable that the student investigator would contact the surrogate, either by person or by telephone, for permission to administer the 
mental status exam. The RIC IRB reported concerns about the consent process and content of the informational letters that were to be given to the patient and surrogate. The process of revising and resubmitting to the Lifespan and RIC IRBs entailed three and five months, respectively. Once approval was obtained from both IRBs, the study

commenced. After one week of data collection, a study participant notified the RIC IRB of her objection to having her husband called for permission to perform the Mini-Cog assessment. At that point, the RIC IRB suspended the study until another procedure could be developed to obtain surrogate permission for assessment. A revised procedure was submitted in which the student investigator would only approach a surrogate while they were visiting the patient in the hospital. This was approved after two weeks and data collection resumed. These delays resulted in a smaller than anticipated number of participants to be interviewed in the available time frame.

\section{Ethical Concerns/Diversity Implications}

Because of the potential for cognitive impairment in the older, hospitalized population, great consideration was given to the ability of the potential participants to provide informed consent. A significant concern was that failure of the Mini-Cog exam could elicit an untoward emotional response from the patient. As part of the verbal consent process, the patient was advised that the Mini-Cog did not necessarily indicate that the patient had dementia. The patient was counseled that sometimes forgetfulness occurs when not feeling well, or could be caused by illness or infection. Participants were told prior to the screening that results would not be reported to their health care provider, unless the patient wanted the information shared with them. If the interview 
caused increased stress or feelings of guilt for the patient or if the subject matter elicited an emotional or angry response from the patient, the patient was referred to the clinical social worker. Risk to the patient was minimal, but the investigator responded to all considerations. As an experienced case manager, the interviewer had the expertise to identify and respond to any patient concerns as they arose. The participants were given the opportunity to withdraw from the interview at any time during the process and were not asked to discuss anything that they identified as making them feel uncomfortable.

\section{IRB}

IRB approval was obtained from Lifespan IRB on December 10, 2012 and Rhode Island College on February 20, 2013.

\section{Outcome Measurement}

The participants responded to open-ended questions that provided descriptive data. Outcomes that were measured were the patient's perceived reasons for hospital readmission. The outcome data were examined among the patients' gender and the support they received at home (caregiver, home health care services).

\section{Evaluation Plan}

The patient's key responses were noted during the interview and later transcribed verbatim. The responses were reviewed and analyzed for common themes by the investigator. Significant statements were extracted. Data were categorized using the qualitative data analysis method of Miles and Huberman (1994).

Miles and Huberman's model was developed in 1994 to analyze qualitative data and provide ways of discerning, examining, comparing and contrasting, and interpreting 
expressive patterns or themes. The goal of qualitative analysis is to obtain results that make sense and categorize the results into themes. Compared to quantitative analysis, in which the numbers are what they stand for and are quantifiable for analysis, qualitative research analysis is guided by words. These words express thoughts and feelings reported by the participants of the survey. There are no incorrect responses. The duty of the researcher throughout the project is to query and examine the results of the survey. By grouping common emerging themes together, the researcher may illuminate broader study questions. If there are deviations from themes or patterns, investigation into the causative factors might explain the responses. The study question may be broadened as interesting stories may emerge from responses. The patterns or findings might suggest that additional data may need to be collected or the study question(s) need to be adjusted. The researcher may find that these patterns or themes that emerge do not corroborate with the corresponding analyses that have already been conducted, and would then need to investigate the reasons for the discrepancies (Miles \&Huberman, 1994).

Miles \& Huberman (1994) describe the major phases of data analysis as data reduction, data display and conclusion drawing and verification (Diagram, Appendix VI). In data reduction, the information gathered needs to be organized and reconfigured. Data reduction refers to "the process of selecting, focusing, simplifying, abstracting and transforming the data that appears in written up field notes or transcriptions" (Miles and Huberman, 1994). The data needs to be manageable and made intelligible in terms of the issues being addressed. Data display provides organization of data that allows one to draw conclusions. It may be in the form of a diagram, chart or text that allows a new way 
of arranging the data that allows the researcher to successfully begin to discern systematic patterns and relationships. At this stage, higher orders themes may emerge that were not obvious during the data reduction phase. Conclusion drawing and verification, the third element of qualitative analysis, involves consideration of what the analyzed data means and what are the inferences. Verification entails revisiting the data as many times as needed to verify the emergent conclusions. "The meanings emerging from the data have to be tested for their plausibility, their sturdiness, their 'confirmability'-that is, their validity” (Miles \& Huberman, 1994, pg 10).

\section{Dissemination Plan}

Results of this research will be disseminated to the key stakeholders at the hospital, including members of the Case Management Department. An oral presentation will be offered to the case management department and transitions team at the hospital in the spring of 2013. The results will also be shared during the National Nurses Week presentations at the hospital. 


\section{Results}

Data were collected during six patient interviews between February, 2013 and April, 2013. Three patients had family members present during the interview process, two family members were spouses and one was a daughter. Two family members declined participation, citing the patients were feeling exhausted or too sick to participate. Other opportunities for sample selection were missed when patients (3) were discharged prior to the student investigator visit and some patients did not have family members or surrogates present. One patient did not pass the Mini-Cog exam. 
Table 1 Patient Characteristics

\begin{tabular}{|lll|}
\hline Patients $(\boldsymbol{n}=\mathbf{6})$ & \\
\hline Gender \% $(n)$ & \\
& \\
$\quad$ Male & $50(3)$ & \\
$\quad$ Female & $50(3)$ & \\
& & \\
Age in years, mean, range & 75.6 & $66-86$ \\
& & \\
Number of days to readmission, & \\
Mean, range & 8.5 \\
& \\
Disease Diagnosis, percent, $(n)$ & \\
HF & $33.3(2)$ & \\
PNA & $33.3(2)$ \\
MI/HF & $16.7(1)$ \\
COPD/HF & $16.7(1)$ \\
\hline
\end{tabular}


Table 2 Survey Responses

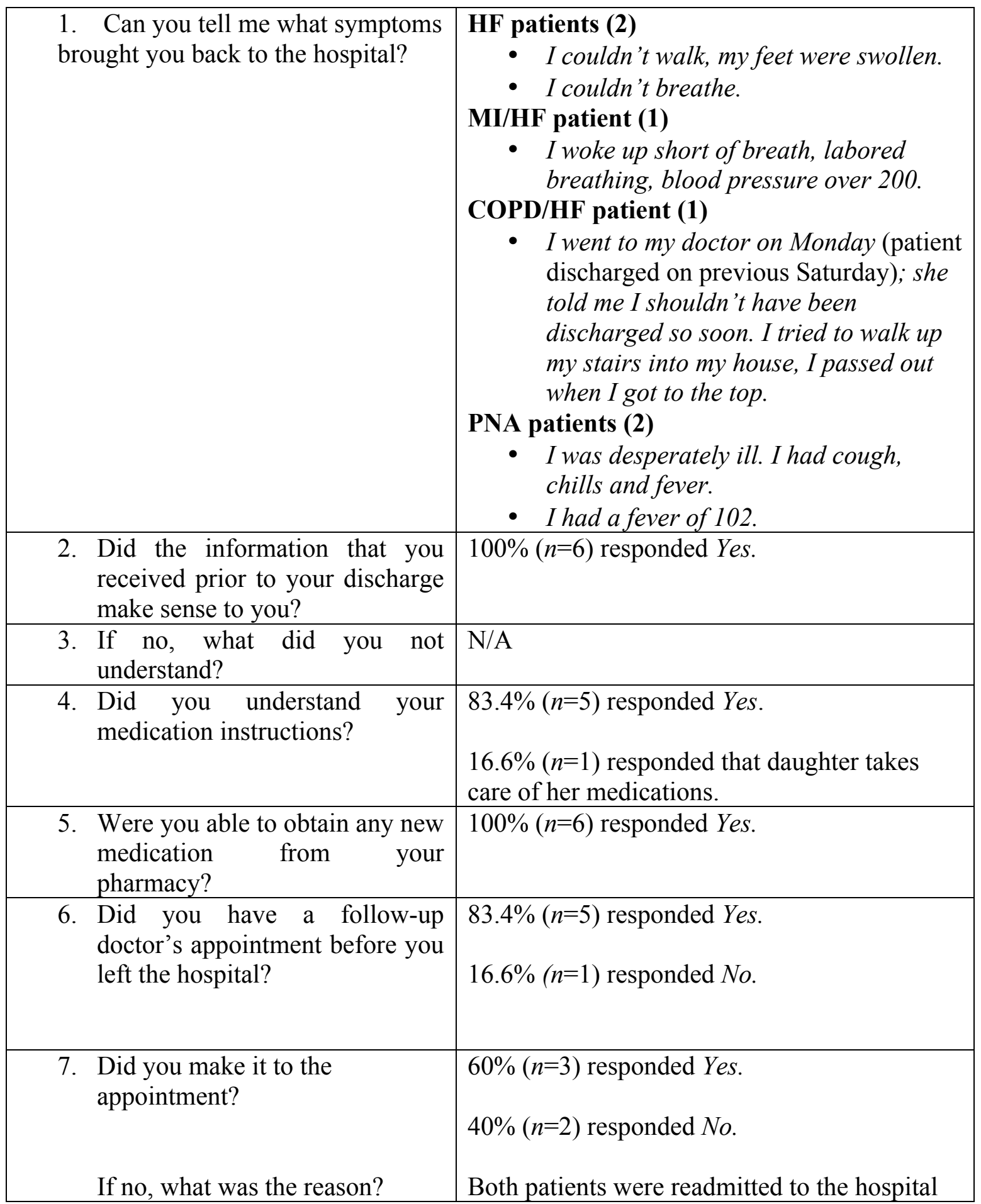




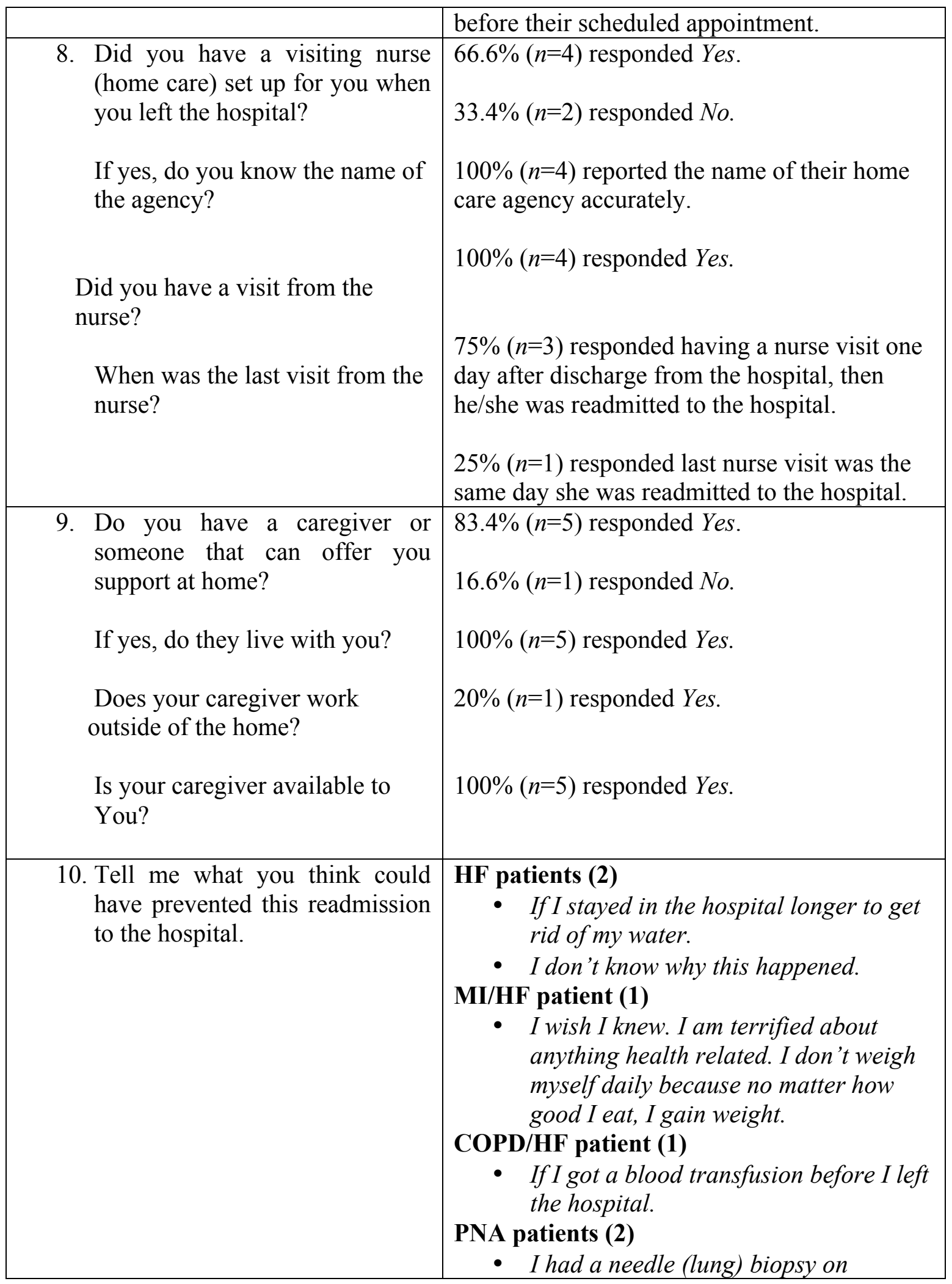




\begin{tabular}{|l|l|}
\hline & $\begin{array}{l}\text { Thursday; they wanted to discharge me } \\
\text { that day, because they said the blizzard } \\
\text { was coming. I didn't want to go that } \\
\text { night, so they came in first thing } \\
\text { Friday morning, and told me I needed } \\
\text { to go before the snow came, so I did } \\
\text { what I was told. I was so sick when I } \\
\text { got home, I went right to bed } \\
\text { Don't come to the hospital in the first } \\
\text { place. }\end{array}$ \\
\hline
\end{tabular}


Table 3 Emerging Themes

\begin{tabular}{|c|c|}
\hline Discharge readiness & $\begin{array}{l}\text { - They (doctors) wanted to discharge } \\
\text { me that day, because they said the } \\
\text { blizzard was coming. I didn't want } \\
\text { to go that night, so they came in first } \\
\text { thing Friday morning, and told me I } \\
\text { needed to go before the snow came, } \\
\text { so I did what I was told. I was so } \\
\text { sick when I got home, I went right to } \\
\text { bed. } \\
\text { - If I stayed in the hospital longer to } \\
\text { get rid of my water. } \\
\text { (My doctor) told me I shouldn't } \\
\text { have been discharged so soon. I } \\
\text { tried to walk up my stairs into my } \\
\text { house; I passed out when I got to } \\
\text { the top. }\end{array}$ \\
\hline Communication & $\begin{array}{l}\text { - I am terrified about anything health } \\
\text { related. } \\
\text { - I did not see a case manager on my } \\
\text { last admission, but someone from a } \\
\text { home care agency came in to visit } \\
\text { me. }\end{array}$ \\
\hline Education & $\begin{array}{l}\text { - I don't weigh myself daily because } \\
\text { no matter how good I eat, I gain } \\
\text { weight. } \\
\text { - I don't eat out at restaurants, it's } \\
\text { too expensive.(Patient later stated he } \\
\text { ate at a fast food restaurant) }\end{array}$ \\
\hline
\end{tabular}




\section{Summary and Conclusions}

A total of six patients at The Miriam Hospital in Providence, RI were interviewed for this survey during the period of February through April of 2013. All of the participants were aged 65 and older and had been readmitted to the hospital within 30 days of discharge from the hospital to their home. They were readmitted with heart failure (HF), myocardial infarction (MI), pneumonia (PNA), or chronic obstructive pulmonary disease (COPD). Patients were identified using the Allscripts computer program. Their electronic medical record was screened for age, diagnosis, cognitive impairment, discharge disposition, length of time between discharge and readmission and ability to speak and understand English. Initially, the student investigator called the patient's surrogate for permission to perform the Mini-Cog exam and to explain the purpose of this study. After a concern was voiced by one of the participants about her spouse being called for permission, it was determined that the student investigator would only approach potential participants who had their family member or surrogate present in their hospital room. Once permission was obtained from the patient's surrogate, the Mini-Cog mental status exam was administered to the participant. When the patient successfully completed the Mini-Cog, an informational letter was provided and the patient was asked to read it. If the family member was present, the informational letter addressed to the family member was provided. At that point, the patient and/or family had the opportunity to decline participation in the survey if they wished. The patients who agreed to participate were asked a series of questions and their key responses were 
noted by the student investigator and expanded on after the interaction ended. During the interview, questions posed by the patient and family were answered. This led to impromptu teaching during two interviews.

A theme that emerged was discharge readiness. While some of the respondents stated they were discharged "too soon," they acknowledged that they were aware that they had a right to appeal the discharge decision, but did not opt for that choice. One patient stated that the doctors wanted to discharge her before an impending blizzard. It appeared to the student investigator that patients do not challenge the doctor's discharge decision.

Another theme that emerged was communication. During a discussion with one patient, she stated that she did not have home care, but she reported a representative from a home care agency did visit her during her last hospitalization. This is not the normal business practice at The Miriam Hospital. Upon further questioning, it was determined that the representative was likely a case manager who worked for the hospital, not a representative from a home care agency.

A third theme emerged: education. While $100 \%$ of the respondents reported that they received and understood their discharge instructions, one patient with a diagnosis of HF stated she did not weigh herself every day because of frustration with a lack of weight loss. The investigator explained to the patient that the purpose of daily weight monitoring was to check for weight gain, related to retained fluid. The student investigator explained to the patient that monitoring fluid in her lower extremities and recording daily weights would provide an indicator of HF. Another respondent with HF 
reported that he followed his low sodium diet and did not eat out in restaurants, citing that "eating out was too expensive." He acknowledged, however, that the evening before readmission, he ate at Burger King, a fast food restaurant, serving high calorie, high sodium foods. The student investigator and patient then discussed food choices that have lower sodium content.

A limitation of this study was the low number of participants. The small sample size related to several factors, such as time constraints secondary to IRB delays and inability to recruit patients without the surrogate being present and the inability of the student investigator to approach patient/surrogate until after normal work hours. 


\section{Recommendations and Implications for Advanced Nursing Practice}

One of the implications of the PPACA is that frequent hospital readmissions for certain diagnoses will result in financial penalties to hospitals in the U.S., many of which already face financial burdens. Further study needs to be done to assess the education and communication needs of the patient population with admission diagnoses of heart failure (HF), myocardial infarction (MI), pneumonia (PNA), or chronic obstructive pulmonary disease (COPD). Jenq and Tinetti (2012) reported that causes of hospital readmissions included the patient's misunderstanding of the discharge instructions, medication omissions or duplications, lack of communication between the hospital and primary care physician, and lack of continued home care and support services (Jenq \& Tinetti, 2012).

Transition teams, which focus on preventing hospital readmissions, need to be implemented in hospitals, and then partner with home care agencies, primary care providers and skilled nursing facilities. By providing input and maintaining communication with the interdisciplinary team: the advanced practice registered nurse (APRN), clinical social worker, physical therapist, occupational therapist, speech therapist, nutritionist, physician, nurse, spiritual supporter, the case manager/discharge planner can collaborate and assist with developing and implementing the most appropriate discharge plan for the patient.

APRNs can provide leadership to the interdisciplinary transition teams. Further, the APRN can facilitate collaboration with patients and post-hospital support services to 
provide increased resources for the patient's disease management post discharge. With a successful program, an advanced practice nurse in a health care organization may prevent unnecessary readmissions by providing more appropriate patient care, reducing the risk of financial penalties for the institution. As discussed in the study by Koeling, Johnson, Cody \&Aaronson (2005), heart failure patients benefitted from enhanced education such as focused teaching by an advanced practice registered nurse for 60 minutes and from follow-up telephone interviews.

The APRN must keep abreast of the latest health care services and technology that are available to assist the patient with a successful transition into their home environment. An APRN experienced in transitional care and patient education can be instrumental in future policy development, at an organizational level as well as through state and local departments of health. Policy and payment initiatives should encourage greater coordination between hospitals, primary care providers and community resources. The APRN can assist in formulating equality improvement partnerships with these providers and Accountable Care Organizations (ACOs), who deliver high-quality care while spending health care dollars more wisely.

Patients will benefit from empowerment through education. If a patient does not feel well enough to be discharged, or has questions for the health care provider, he/she should be supported to share their concerns. Families should be encouraged to do the same, if the patient is unwilling or unable. The inclusion of family members or caregivers in discharge planning and education is imperative. As found in the literature review by Bauer, Fitzgerald, Hausler \& Manfrin (2009), elderly patients showed 
improved outcomes and a decrease in hospital readmissions when the caregivers participated in the educational process (Bauer, Fitzgerald, Hausler \& Manfrin , 2009).

The development of an enhanced case management model may be advantageous to the hospital in preventing readmissions. By training case managers to be sensitive to the elderly patients and caregivers discharge needs, appropriate services and programs can be initiated prior to the patient's discharge. In the "discharge management" model by Steeman, Moons, Milisen, de Bal, de Geest, de Froidmont, Tellier, Gossett \& Abraham (2006), patients who received the enhanced management services, in addition to the usual case management services, showed a decline in hospital readmissions (Steeman, et al, 2006).

Cultural consideration needs to be addressed when nurses are educating a patient and formulating a discharge plan. Written education materials need to be available in languages other than English, and the patient needs to be assessed for literacy. When educating a non-English speaking patient, it is imperative to have a medical interpreter, not a family member, explain discharge instructions to the patient. The health care team also needs to consider and understand the cultural background of a patient when educating the patient/family about disease management.

Although the study had limited participants, the student investigator learned that many factors can affect a patient's success after discharge to home. By employing Roy's Adaptation Model (Roy \& Andrews, 1999), the investigator learned that the patient's awareness of self and environment is embedded in thinking and feeling, and that system relationship, such as the transition from hospital to home, includes fostering of 
interdependence and integration of environment resulting in adaptation. By understanding the range of educational and emotional needs of the patient, nurses can play an important role in of an elderly patient's successful discharge transition to home and avoid hospital readmission. 


\section{References}

Ahmed, O., Rak, D. (2010). Hospital readmission among participants in a transitional case management program. The American Journal of Managed Care, 16(10), 778-783.

American Technology Association (2006). Telemedicine, Telehealth and Information Technology. Retrieved from http://www.americantelemed.org/files /public/policy/HIT

Amercan Nurses Association (2012). New Medicare provisions to recognize and pay for core nursing services. Retrieved from http://nursingworld.org/homepage/category/nursing insider/archieve_1/2012NI/Nov-2012

Askren-Gonzalez, A. \& Frater, J. (2012). Case management programs for hospital readmission prevention. Professional Case Management, 17(5), 219-226.

Bauer, M., Fitzgerald,L., Haesler, E., \&Manfrin, M. (2009). Hospital discharge of the planning for frail older people and their family: Are we delivery best practice? A review of evidence. Journal of Clinical Nursing, 18, 2539-2546.

Berry, D., Costanzo, D., Elliot, B., Miller, B., Miller, J., Quackenbush, P., Su, Y. (2011). Preventing avoidable hospitalizations. Home Healthcare Nurse. 29(9), 540-549.

Carolan Doerflinger, D. (2007). Mental status assessments of older adults: the Mini-Cog. Best Practices in Nursing Care to Older Adults. The Hartford Institute of Geriatric Nursing. Issue No. 3. 
Centers for Medicare and Medicaid Services (2012). Readmission Reduction Program. Retrieved from https://www.cms.gov.Medicare/Meidcare-Fee-for-ServicePayment/Acute InpatientPPS?Readmission-Reduction-Program.html

Coleman, E. (2003). Falling through the cracks: challenges and opportunities for improving transitional care for persons with continuous complex care needs. Journal of the American Geriatric Society, 51, 549-555.

Dharmarajan, K., Hsieh, A., Lin, Z., Bueno, H., Ross, J., Horwitz, L., Barreto-Filho, J., Kim, N., Bernheim, S., Suter, L., Drye, E., Krumholz, H. (2013). Diagnoses and timing of 30-day readmissions after hospitalizations for heart failure, acute myocardial infarction, or pneumonia. Journal of the American Medical Association,309(4), 355-363.

Ditewig, J., Blok, H., Havers, J., \& van Veenendaal. (2009). Effectiveness of selfmanagement interventions on mortality, hospital readmissions, chronic heart failure hospitalization rate and quality of life in patients with chronic heart failure: A systematic review. Patient Education and Counseling, 78, 297-315.

Dobrzanska, L., \& Newell, R. (2006). Readmissions: A primary care examination of reasons for readmission of older people and possible readmission risk factors. Journal of Clinical Nursing, 15, 599-606.

Forster, A., Clark, H., Menard, A., Dupuis, N., Chernish, R., Chandok, N., \& Glass, N., vanWalraven, C. (2004). Adverse events among medical patients after discharge from hospital. Canadian Medical Association Journal, 170(3), 345-349. 
Moss, C., Ogle, R. (2012). A person-centered lifestyle change intervention model: working with older people experiencing chronic illness. International Journal of Nursing Practice, 18, 379-387.

Graham, J., Tomcavage, J., Salek, D., Sciandra, J. Davis, D., \& Stewart, W. (2012). Post discharge monitoring using interactive voice response system reduces 30-day readmission rates in a case-managed Medicare population. Medical Care, 50(1), $50-57$.

Hackbarth, G. (2009). Reforming America's health care delivery system. Medicare Payment Advisory Council. Retrieved from www.medpac.gov

Jack, B., Chetty, V., Anthony, D., Greenwald, J., Sanchez, G., Johnson, A., Forsythe, S., O’Donnell, J., Paasche-Orlow, M., Manasseh, C., Martin, S., \& Culpepper, L. (2009). A reengineered hospital discharge program to decrease rehospitalization. Annals of Internal Medicine, 150, 178-187.

Jencks, S., Williams, M., \& Coleman, E. (2009). Rehospitalizations among patients in the Medicare fee-for-service program. The New England Journal of Medicine, $360,1418-1428$.

Jenq, G., Tinetti, M. (2012). The journey across the health care (dis)continuum for vulnerable patients. Journal of the American Medical Association, 307 (20), 2157-2158.

Joynt, K.\& Jha, A. (2012). Thirty-day readmissions-truth and consequences. New England Journal of Medicine. 366(15), 1366-1369. 
Joint Commission, The. (2012). Heart failure core measure set. Retrieved from http://www.joint commission.org/assets/1/6/Heart\%20Failure.pdf

Kansagara, D., Englander, H., Salanitro, A., Kagen, D., Theobald, C., Freeman, M. \& Kripalani, S. (2011). Risk prediction models for hospital readmission: A systematic review. The Journal of the American Medical Association, 306, 1688-1698.

Koeling, T., Johnson, M., Cody, R., \& Aaronson, K. (2005). Discharge education improves clinical outcomes in patients with chronic heart failure. Circulation Journal of the American Heart Association, 111, 179-185.

Krumholz, H. (2013). Post-hospital syndrome-an acquired, transient condition of general risk. New England Journal of Medicine, 368(2), 100-102.

Lagoe, R., Noetscher, C., \& Murphy, M. (2001). Hospital readmission: Predicting the risk. Journal of Nursing Care Quality, 15(4), 69-83.

McHugh, M., \& Ma, C. (2013). Hospital nursing and 30-day readmissions among Medicare patients with heart failure, acute myocardial infarction, and pneumonia. Medical Care. 51(1), 52-59.

Meek, J.A. (2012). Affordable care act predictive modeling challenges and opportunities for case management. Professional Case Management. 17(1), 15-21.

Miles, M.B. \& Huberman, A.M. (1994). Qualitative Data Analysis (2 ${ }^{\text {nd }}$ ed.). Thousand Oaks, CA: Sage Publications. 
Rau, J. (2012). Medicare revises hospital's readmission penalties. Kaiser Health News. Retrieved from ttp://www.kaiserheatlhnews.org/stories/2012/October/03/medicare -revised-hospitals-readmissions-penalties.aspx.

Roy, C. \&Andrews, H.A. (1999). The Roy Adaptation Model ( $2^{\text {nd }}$ ed.). Stamford, CT: Appleton \& Lange.

Schmeida, M., \& Savrin, R. (2012). Heart failure rehospitalization of the Medicare FFS patient a state-level analysis exploring 30-day readmission factors. Professional Case Management, 17(4), 155-161.

Schmeida, M. \& Savrin, R. (2012). Pneumonia rehospitalization of the Medicare fee-forservice patient a state level-analysis : exploring 30-day readmission factors. Professional Case Management 17(3), 126-131.

Slayter, S., Toye, C., Popescu, A., Young, J., Matthews, A., Hill, A., \& Williamson, D. (2013). Early re-presentation to hospital after discharge from an acute medical unit : perspectives of older patients, their family caregivers and health professionals. Journal of Clinical Nursing, 22, 445-455.

Smith, S., \& Alexander, J. (2012). Nursing perception of patient transitions from hospitals to home with home health. Professional Case Management, 17(4), 175185.

Steeman, E., Moons, P., Milisen, K., De Bal, N., De Geest, S., De Froidmont, C., Tellier, V., Gossett, C., \&Abraham, I. (2006). Implementation of discharge management for geriatric patients at risk of readmission or institutionalization. International Journal for Quality Health Care, 18(5), 352-358. 
Stone, J. \& Hoffman, G. (2010). Medicare hospital readmissions: issues, policy options and PPACA. Congressional Research Service. Take steps now to reduce readmissions, ED visits within 30 days (May, 2009). Hospital Case Management, 17(5), 65-80.

Terry, K. (2012). Accountable care organizations step up to Medicare's challenge. Retrieved from http://www.informationweek.com/news/healthcare/ policy $/ 240003586$

Van Such, M., Naessens, J., Strobel, R., Huddleson, J. \& Williams, A. (2006). Effect of discharge instructions on readmission of hospitalized patients with heart failure: do all of the Joint Commission on Accreditation of Healthcare Organization's heart failure core measure reflect better care? Quality and Safety in Health Care. $15,414-417$.

Watkins, L., Hall, C., \& Kring, D. (2012). Hospital to home a transition program for frail older adults. Professional Case Management, 17(3), 117-123. 
STATES WITH THE HIGHEST 30-DAY READMISSION RATES

$>$ District of Colombia $23.2 \%$

$>$ Louisiana $21.9 \%$

$>$ Illinois $21.7 \%$

$>$ West Virginia

$21.3 \%$

$>$ Kentucky

$21.2 \%$

STATES WITH THE LOWEST 30-DAY READMISSION RATES

$>$ Idaho

$13.3 \%$

$>$ Utah

$14.2 \%$

$>$ Oregon

$15.7 \%$

$>$ New Mexico

$16.3 \%$

$>$ New Mexico

$16.2 \%$

Alaska

$16.2 \%$

Rehospitalizations After Discharge from the Hospital
Among Patients in Medicare Fee-for-Service Programs

Percent of patients rehospitalized (cumulative)

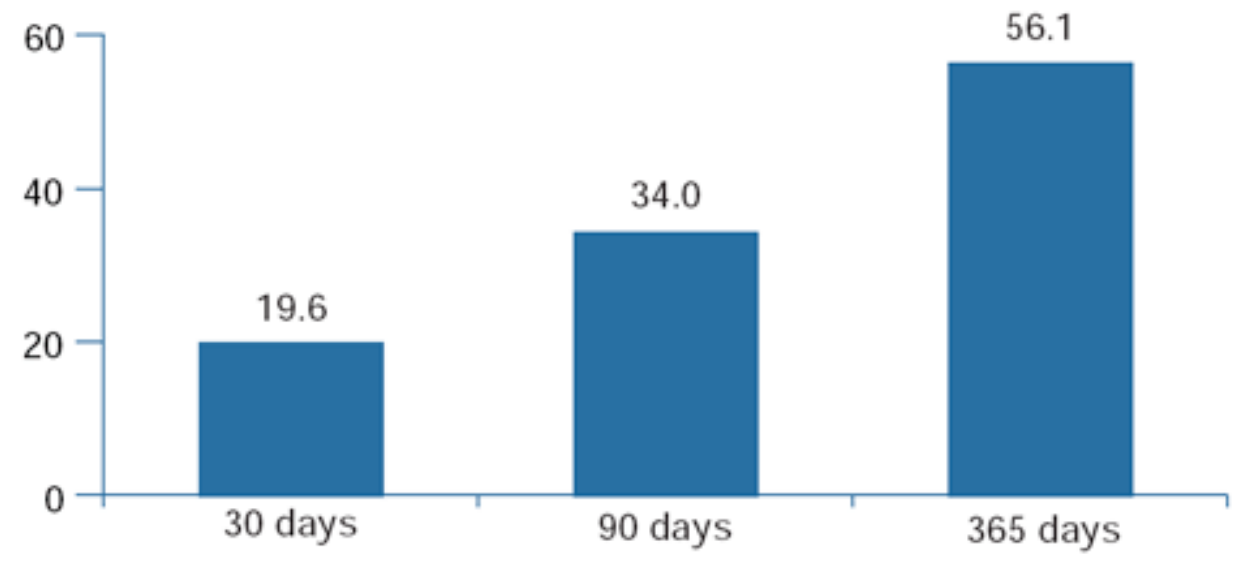

Number of days following discharge from hospital

Source: Adapted from S. F. Jencks, M. V. Williams, and E. A. Coleman, "Rehospitalizations Among Patients in the Medicare Fee-for-Service Program," New England Journal of Medicine, Apr. 2, 2009 360(14):1418-28. 


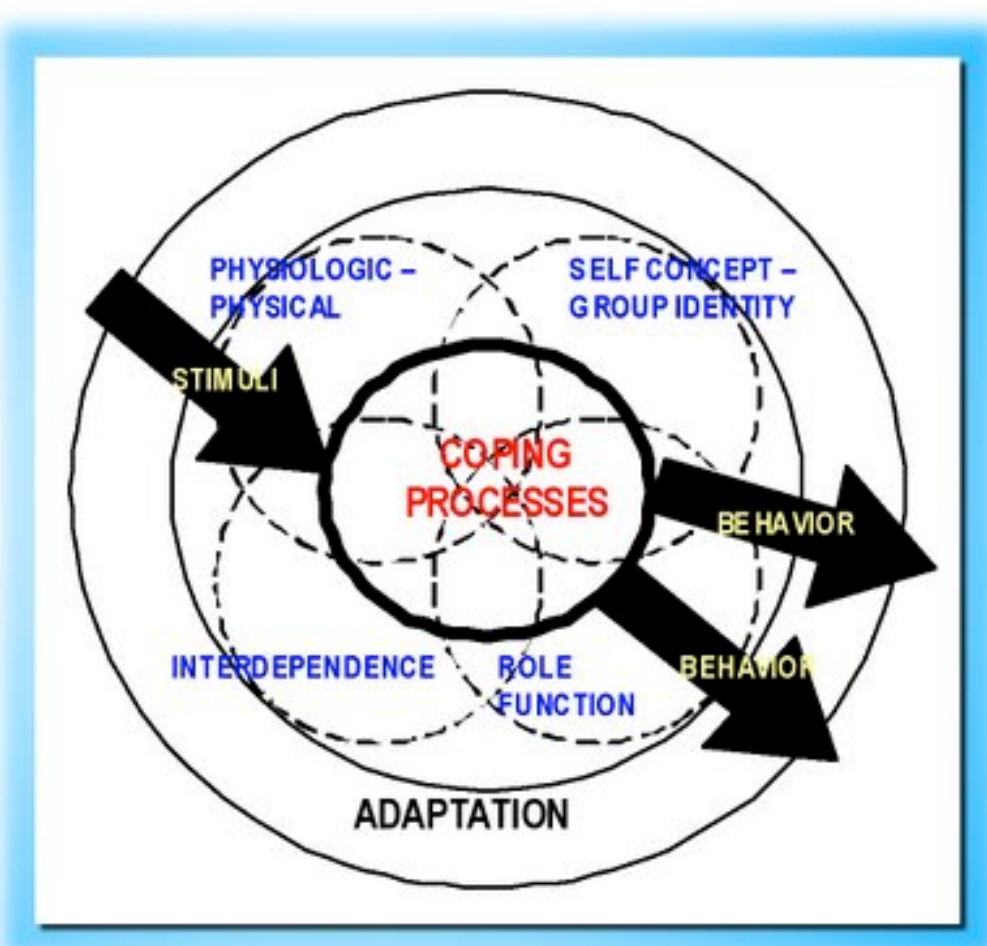

Roy Adaptation Model (1999) 


\section{Appendix III}

\section{The Mini-Cog Assessment for Dementia}

\section{Administration}

The test is administered as follows:

1. Instruct the patient to listen carefully to and remember 3 unrelated words and then to repeat the words.

2. Instruct the patient to draw the face of a clock, either on a blank sheet of paper or on a sheet with the clock circle already drawn on the page. After the patient puts the numbers on the clock face, ask him or her to draw the hands of the clock to read a specific time.

3. Ask the patient to repeat the 3 previously stated words.

Scoring

Give 1 point for each recalled word after the CDT distracter.

Patients recalling none of the three words are classified as demented (Score $=0$ ).

Patients recalling all three words are classified as non-demented (Score $=3$ )

Patients with intermediate word recall of 1-2 words are classified based on the CDT

(Abnormal $=$ demented;

Normal $=$ non-demented)

Note: The CDT is considered normal if all numbers are present in the correct sequence and position, and the hands readably display the requested time.

Figure 1. The Mini-Cog scoring algorithm. The Mini-Cog uses a three-item recall test for manory and the intuitive clock-drawing test. The latter serves as an "infornative distractor,"

helping to clarity scores when the memory recall score is intermediate.

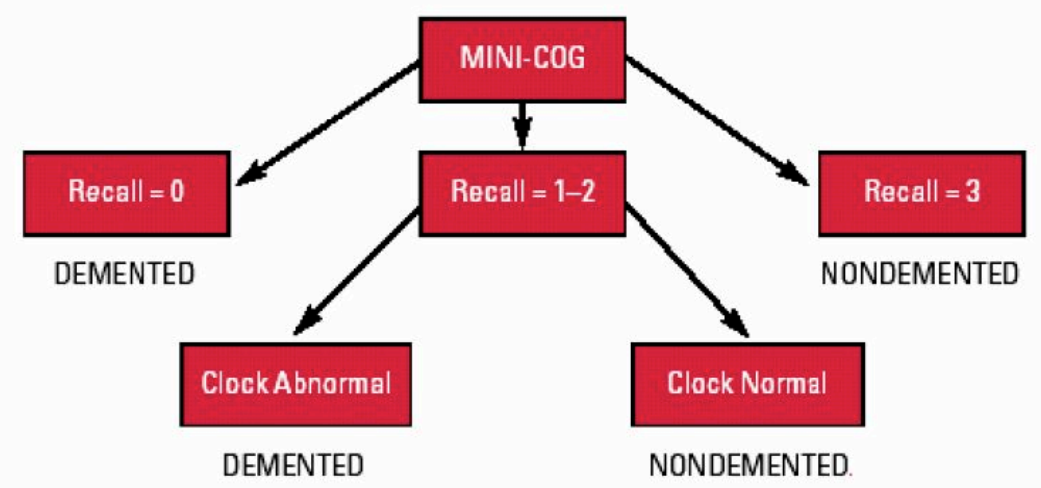


From Borson, S., Scanlan, J., Brush, M., Vitallano, P., \& Dokmak, A. (2000). The Mini-Cog: A cognitive 'vital signs' measure for dementia screening in multi-lingual elderly. International Journal of Geriatric Psychiatry, 15(11), 1021-1027.

\section{APPENDIX IVDear Miriam Hospital Patient,}

My name is Susan Amalfitano. I am a graduate nursing student at Rhode Island College (RIC) and work at The Miriam Hospital (TMH). I am conducting a research study about hospital readmissions Dr. Cynthia Padula, a nurse researcher at TMH and a professor at RIC, is supervising this research study. You are being asked to participate in a voluntary research study entitled, "Contributing Factors to Hospital Readmissions." You were identified as a potential participant because you were readmitted into the hospital within 30 days of your discharge from the hospital. The purpose of this study is to evaluate the patient's perception on the reasons for hospital readmission.

If you agree to participate, here is what will happen. You will be asked a few questions. Based on your responses to the questions, you may be asked a series of questions about your last hospital stay or you may be thanked for your time and no further participation will be requested. This survey will take approximately 20-30 minutes.

We are asking that you participate in this study by completing this survey. We will not be collecting any information that can be used to identify you and no one other than the researcher will know who chose to participate in the survey or who declined to do so. You have the right not to participate in this survey. Your decision to participate or not to participate will have no impact on your care at the hospital. All data will be treated as confidential, and will be safeguarded according to the policy of the Lifespan institution. This policy is based on Rhode Island law, which promotes protection of confidential health information. The information that is collected will be stored in a locked cabinet at The Miriam Hospital and only the researcher and principal investigator will have access to the secured files.

If you have any questions about this research study, you may contact the principal investigator, Dr. Cynthia Padula, at (401) 456-9720. If you have any complaints about your taking part in this study, or would like more facts about the rules for research studies, or the rights of people who take part in research studies, you may contact either Patricia E. Houser, in the Lifespan Office of Research Administration at (401) 444-6346 or Christine Marco, $\mathrm{PhD}$, of the Rhode Island College Institutional Review Board at 
(401) 456-8598 or email IRB@ric.edu. If you are feeling distress over this survey, you may contact your clinical social worker at The Miriam Hospital at (401)-793-2085.

By participating in this interview, you are agreeing to participate in this study. If you do not wish to participate in this study, simply inform the interviewer.

Thank you.

Information letter for patient questionnaire Contributing Factors to Hospital Readmissions 


\section{Appendix IVa}

Dear Family Member of Miriam Hospital Patient,

My name is Susan Amalfitano. I am a graduate nursing student at Rhode Island College (RIC) and work at The Miriam Hospital (TMH). I am conducting a research study about hospital readmissions. Dr. Cynthia Padula, a nurse researcher at TMH and a professor at RIC, is supervising this research study. You are being asked to participate in a voluntary research study entitled, "Contributing Factors to Hospital Readmissions." You were identified as a potential participant because your family member was readmitted into the hospital within 30 days of his/her discharge from the hospital. The purpose of this study is to evaluate the patient's and family's perception on the reasons for hospital readmission.

If you agree to participate, here is what will happen. You will be asked a series of questions about your family member's last hospital stay. This survey will take approximately 20-30 minutes.

We are asking that you participate in this study by completing this survey. We will not be collecting any information that can be used to identify you or your family member and no one other than the researcher will know who chose to participate in the survey or who declined to do so. This is a voluntary survey. You have the right not to participate in this survey. Your decision to participate or not to participate will have no impact on your family member's care at the hospital. There is no risk to the patient. All data will be treated as confidential, and will be safeguarded according to the policy of the Lifespan institution. This policy is based on Rhode Island law, which promotes protection of confidential health information. The information that is collected will be stored in a locked cabinet at The Miriam Hospital and only the researcher and principal investigator will have access to the secured files.

If you have any questions about this research study, you may contact the principal Investigator, Dr. Cynthia Padula, at (401) 456-9720. If you have any complaints about your taking part in this study, or would like more facts about the rules for research studies, or the rights of people who take part in research studies, you may contact either Patricia E. Houser, in the Lifespan Office of Research Administration at (401) 444-6346 or Christine Marco, $\mathrm{PhD}$, of the Rhode Island College Institutional Review Board at 
(401) 456-8598 or email IRB@ric.edu. If you are feeling distress over this survey, you may contact your clinical social worker at The Miriam Hospital at (401)-793-2085.

By participating in this interview, you are agreeing to participate in this study. If you do not wish to participate in this study, simply inform the interviewer.

Thank you.

Information letter for surrogate questionnaire

Contributing Factors to Hospital Readmissions 


\section{Appendix V \\ Contributing Factors to Hospital Readmission Survey Questionnaire}

Today's Date

Patient's Age

Male___ Female

Lives alone Lives with someone else (relationship)

Chronic Disease Diagnosis

Length of time between hospital discharge and readmission

1. Can you tell me what symptoms brought you back to the hospital?

2. Did the information that you received prior to your discharge make sense to you?

3. If no, what did you not understand?

4. Did you understand your medication instructions?

If no, what did you have difficulty with? 
5. Were you able to obtain any new medications from your pharmacy?

If no, were the reason(s) related to:

Cost of the medication?

Lack of transportation to get to the pharmacy?

Other:

6. Did you have a follow-up doctor's appointment before you left the hospital?

Did you make it to the appointment?

If no, what was the reason?

Forgot

Needed to reschedule

No transportation

Other:

7. Did you have a visiting nurse (home care) set up for you when you left the hospital?

If yes, do you know the name of the agency?

Did you have a visit from the nurse? YES

NO

When was the last visit from the nurse?

8. Do you have a caregiver or someone who can offer you support at home?

If yes, do they live with you? YES___ NO

Does your caregiver work outside the home? YES__NO_

Is your caregiver available to you? YES___NO 
9. Tell me what you think could have prevented this readmission to the hospital.

\section{Appendix VI}

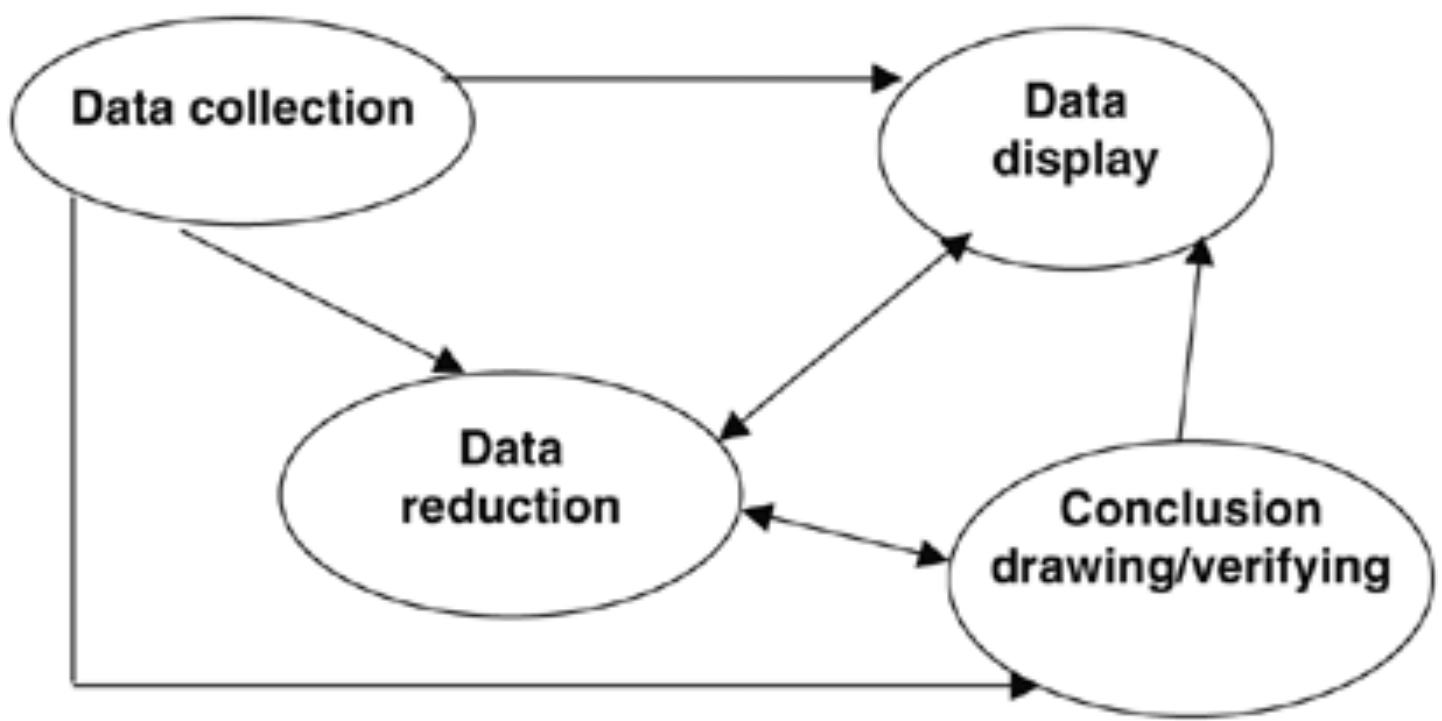


Miles and Huberman, Qualitative Data Analysis, (1994) 
